\title{
Escrita Coletiva: o potencial de um Groupware via Web ${ }^{*}$
}

\author{
Prof $^{\mathrm{a}}$. Dr ${ }^{\mathrm{a}}$. Patricia Alejandra Behar ${ }^{* *}$ \\ Ms. Alexandra Lorandi Macedo ${ }^{* \star \star}$ \\ Jossiane Boyen Bitencourt ${ }^{* * * *}$ \\ Sandra Bordini Mazzocato ${ }^{\star * * * *}$
}

Resumo: O presente artigo descreve o processo de construção de um editor voltado para a escrita cooperativa/colaborativa via Web. O ETC - Editor de Texto Coletivo - foi desenvolvido pelo NUTED/UFRGS (Núcleo de Tecnologia Digital aplicada à Educação da Universidade Federal do Rio Grande do Sul). O seu objetivo é dar suporte à elaboração de um texto de forma síncrona elou assíncrona por autores dispersos geograficamente. Sendo assim, o editor fornece ferramentas para a negociação, coordenação das ações e comunicação entre os participantes. Logo, trata-se de um ambiente com potencial para acompanhar o processo de construção da coletividade.

Palavras-chave: Escrita Coletiva, Cooperação/Colaboração, Aprendizagem.

\section{Collective Writing: a Web supported Groupware's potential}

Abstract: The present article describes the process of a text editor development towards a distance cooperative/collaborative writing. The ETC - Editor de Texto Coletivo (Collective Text Editor) - has been made by NUTED/UFRGS (Núcleo de Tecnologia Digital aplicada à Educação of the Federal University of Rio Grande do Sul). The editor's main objective is to support synchronous and not-synchronous text creating by authors who are geographically dispersed. That way, the editor supplies for its users, communication, action coordination and negotiation tools. Therefore, the ETC is an environment able to encourage the collectivity construction process.

Keywords: Collective Writing, Cooperation/Collaboration, Learning.

\section{Introdução}

Este artigo tem como objetivo apresentar o ETC, bem como seus recursos com potencial para a construção da coletividade. Para isso, pretende-se apontar os aspectos referentes ao seu planejamento e processo de construção, abordando seus princípios teóricos e técnicos, finalizando com a apresentação das telas e experiência com o editor. Quanto aos princípios teóricos, são apontados os fundamentos pedagógicos utilizados, tomando-se como pressuposto a necessidade da construção de ferramentas que promovam a cooperação/colaboração. Nos princípios técnicos são especificadas as tecnologias utilizadas na implementação do editor, procurando tornar o trabalho mais ágil e eficiente. Em seguida, parte-se para uma explicação do funcionamento do ETC, bem como exposição de algumas de suas telas e características principais, como os recursos personalizáveis. Além disso, também são apresentadas suas funcionalidades.

\footnotetext{
${ }^{*}$ Esta pesquisa conta com o apoio financeiro da Universidade Federal do Rio Grande do Sul (UFRGS).

** Dr ${ }^{a}$ em Ciência da Computação (UFRGS); Prof ${ }^{a}$ Adjunta da Faculdade de Educação e dos Programas de PósGraduação em Educação e em Informática na Educação (UFRGS); Coordenadora do Núcleo de Tecnologia Digital aplicada à Educação (NUTED/UFRGS). pbehar@terra.com.br

***Doutoranda em Informática na Educação (PPGIE/UFRGS); Ms. em Educação (UFRGS), Graduada em Pedagogia (UCS); pesquisadora do NUTED/UFRGS. alorandimacedo@gmail.com

****Mestranda em Educação (UFRGS); Graduada em Pedagogia - Multimeios e Informática Educativa (PUCRS); pesquisadora do NUTED/UFRGS. jboyen@gmail.com

***** Graduada em Publicidade e Propaganda (UFRGS); pesquisadora do NUTED/UFRGS. sandrabordini@gmail.com V. $4 \mathrm{~N}^{\circ} 1$, Julho, 2006
} 
Finalizando, faz-se um breve relato sobre a utilização do ETC para fins de avaliação do groupware, com levantamento de dados parciais.

\section{Construção e Planejamento}

O Editor de Texto Coletivo (ETC) tem como objetivo proporcionar um ambiente capaz de dar suporte à escrita cooperativa/colaborativa através da Web. Logo, foi criado um espaço virtual para que usuários a distância possam elaborar textos de forma síncrona e/ou assíncrona. Tanto a concepção quanto a elaboração do editor apoiou-se numa perspectiva de construção do conhecimento e coordenação de ações baseadas na teoria piagetiana (Piaget, 1995; 1973). Suas ferramentas foram planejadas para apoiar este paradigma a fim de promover a escrita coletiva. $\mathrm{O}$ editor foi constituído por uma equipe interdisciplinar, composta por profissionais de diferentes áreas (educação, computação e webdesign). Considera-se que este trabalho interdisciplinar trouxe benefícios ao groupware desenvolvido, uma vez que o confronto de perspectivas (das áreas humanas, exatas e aplicadas) agregou ao editor um embasamento consistente a nível de planejamento e desenvolvimento de groupware, design e do ponto de vista educacional. Destaca-se que o ETC foi desenvolvido em duas diferentes versões: uma integrada à plataforma oficial de educação a distância da UFRGS, o ROODA (Rede cOOperativa de Aprendizagem da Universidade Federal do Rio Grande do Sul) e a outra stand alone. A primeira pode ser instalada sem a necessidade de outras ferramentas que um ambiente a distância fornece, o que a torna mais leve para servidores não muito robustos. A segunda versão será uma funcionalidade a ser incorporada à plataforma ROODA, isto é, mais um recurso de apoio neste ambiente virtual de aprendizagem.

O planejamento do ETC ocorreu durante todo o semestre 01/2005, com encontros semanais. Tomou-se como base sua versão anterior que foi utilizada com alunos das disciplinas EDU3375 - O Computador na Educação (Disciplina oferecida pelo curso de Pedagogia/FACED/UFRGS - 02/2002) e de Ambientes de Aprendizagem Computacionais (Disciplina oferecida pelo curso de Pós- Graduação em Educação e pelo Pós- Graduação em Informática na Educação/UFRGS - 01/2002). Através da análise dos dados coletados, viu-se a necessidade de incorporar novas funcionalidades e aperfeiçoar as existentes. $\mathrm{O}$ banco de dados que apresentava inconsistências foi corrigido com o objetivo de evitar problemas técnicos. A atual versão do ETC corrigiu estes problemas a fim de possibilitar melhores condições à escrita cooperativa/colaborativa, ao processo de negociação de diferentes pontos de vista e a própria programação de todo o sistema.

Logo, o ETC encontra-se em sua terceira versão; a primeira foi desenvolvida em 2001 (Behar et al., 2003). A partir de sua utilização em cursos de graduação e pós-graduação da Universidade Federal do Rio Grande do Sul (UFRGS), sentiu-se a necessidade de incorporar novas funcionalidades, bem como aprimorar as já existentes. Porém, como o código de programação das primeiras versões não havia sido comentado e ainda, foram detectados problemas com a base de dados, partiu-se para um novo modelo de planejamento e desenvolvimento do ETC. Sua programação apoiou-se em Linux, baseado na Filosofia de Software Livre. Esta perspectiva vai ao encontro da proposta de inclusão digital, uma vez que seu acesso é facilitado. Além disso, seu código fonte é aberto proporcionando assim, que outros usuários possam contribuir com seu desenvolvimento, além de adaptá-lo às próprias necessidades.

A fim de disponibilizar recursos que favoreçam as interações no editor, foram incorporadas ferramentas de comunicação síncronas (A2, bate-papo) e assíncronas (fórum) que apóiem o processo de cooperação/colaboração e negociação. Outro aspecto fundamental foi a implementação de dois tipos de autoria: única (cada usuário é dono do seu parágrafo/seção e não pode apagar/alterar o parágrafo do outro) e coletiva (todos os 
usuários são responsáveis pelo parágrafo/seção). Através da escolha de autoria, o ambiente pretende ser útil a diferentes públicos-alvo e se adequar às diferentes realidades.

Tanto a concepção quanto a elaboração do editor apoiou-se numa perspectiva de construção do conhecimento e coordenação de ações propostas pela teoria piagetiana (Piaget, 1995; 1973). Assim, buscou-se desenvolver ferramentas que apoiassem esse movimento na busca de auxiliar a escrita coletiva.

A seguir são descritos os princípios teóricos e técnicos que sustentaram a construção do editor ETC. O artigo também apresenta a descrição de algumas telas do editor, suas funcionalidades e finaliza com perspectivas de trabalhos futuros na implementação do mesmo.

\section{Fundamentação Teórica}

A perspectiva de desenvolvimento deste Editor entende o coletivo a partir da articulação de habilidades interpessoais. Isto é, os sujeitos atuam como parceiros no processo de aprendizagem a fim de alcançar um objetivo comum. Neste movimento dinâmico de troca, encontram-se diferentes culturas e perspectivas, onde os autores interagem de forma aberta e dinâmica.

Neste sentido, a interação é vista como um processo complexo de troca, onde o sujeito modifica suas estruturas cognitivas e pode vir proporcionar a modificação das estruturas dos outros. É através das interações que o sujeito desencadeia um processo interno de construção, possibilitando às pessoas compartilharem idéias e gerar novas interações. Quando este processo ocorre entre duas ou mais pessoas, pode-se chegar a constituir situações de cooperação.

Para Piaget “... cooperar na ação é operar em comum, isto é, ajustar por meio de novas operações (qualitativas ou métricas) de correspondência, reciprocidade ou complementaridade, as operações executadas por cada um dos parceiros." (1973, p. 105). Para o autor, a cooperação supõe: descentração fundamental (condição de agrupamento operatório). Este consiste em ajustar as ações umas às outras até compor sistemas gerais aplicáveis à todas as transformações. Tais sistemas permitem unir as operações de um indivíduo às do outro.

A construção coletiva de um texto apoiada na cooperação é regida pelo equilíbrio e pela coordenação dos pontos de vista. Porém, as condições necessárias para tal equilíbrio são: escala comum de valores (sujeitos compreendem os signos utilizados pelo grupo); igualdade geral dos valores (onde existe a conservação dos valores de troca) e, por fim, não contradição dos valores virtuais trocados anteriormente.

Nesta abordagem, o texto coletivo não é considerado como um aglomerado de informações, mas como um todo correspondente, recíproco e complementar construído a partir de inúmeras trocas interindividuais. Logo, entende-se o "texto" enquanto processo, apoiado nos recursos da tecnologia digital, neste caso específico o ETC.

Nesse sentido a construção de um texto coletivo parte da articulação de idéias de vários sujeitos. Assim, “... a pluralidade dos homens encontra seu sentido não numa multiplicação quantitativa dos 'eu', mas naquilo em que cada um é o complemento necessário do outro.” (Bakhtin, 2000, p. 14-15).

O ETC proporciona aos sujeitos uma relação lingüística aberta a partir de constantes reconstruções das escritas postadas pelos outros. Desta forma, as interferências nesta escrita são uma constante. Este cenário representa o processo criativo da palavra, de maneira que as contribuições trazidas para o texto são construções individuais/coletivas. Assim, “... O limite não é o eu, porém o eu em correlação com outras pessoas, ou seja, eu e o outro, eu e tu." (ibidem, p. 411) 
A construção coletiva de um texto tem como característica principal a multiplicidade de vozes, a dinamicidade das negociações e acordos diante das diferentes perspectivas. Nesse sentido, a condição de "proprietário" da escrita vai de encontro com os objetivos norteadores do ETC. Os mesmos proporcionam condições para a efetivação das trocas entre os sujeitos e para uma construção conjunta. A relação com o outro na escrita coletiva pode permitir uma valorização do processo coletivo de construção, potencializando a crítica e a autonomia durante a (re)construção.

O Editor como um todo, pode ser considerado um groupware, uma vez que suas ferramentas potencializam a escrita coletiva e tem como principal característica criar aplicações de hardware e software que possibilitam o diálogo entre as pessoas a partir de interações. O groupware pode ser situado em duas áreas de estudo: CSCW (Computer Supported Collaborative Work) e CSCL (Computer Supported Collaborative Learning). A primeira tem seu foco de estudo no trabalho em grupo e suas técnicas de comunicação aliadas à tecnologia, uma vez que, sua atenção está voltada ao resultado. Já o CSCL é uma área voltada à aprendizagem em grupo, ou seja, dá-se ênfase ao processo de ensino-aprendizagem realizado através do coletivo. No caso de ser utilizado em âmbito empresarial, o mesmo apoiará o trabalho coletivo, por exemplo, no desenvolvimento de uma ata, de um contrato, documento, planilha, entre outros. O conjunto de funcionalidades desta ferramenta tem como objetivo auxiliar na comunicação e desenvolver a autonomia participativa, bem como a autoria dos sujeitos participantes.

\section{Aspectos Técnicos}

O ETC foi construído em linguagem PHP/4.3.11, que é interpretada em um software servidor Apache/2.0.54 (Gentoo/Linux). Os dados do ETC são armazenados em uma base de dados MySQL/4.0.24 e utilizam, na sua construção, tecnologias voltadas ao cliente, como JavaScript, Dynamic HTML, Cookies entre outras. Todas estas proporcionam uma maior flexibilidade e um grande número de recursos para páginas na Web, mas trazem consigo algumas desvantagens. Exemplo disto é que nem todos os browsers dão suporte a esses tipos de recursos de forma padronizada, o que limita o uso destas tecnologias. Visando proporcionar sua utilização nos mais diferentes navegadores $W e b$, o ETC, em sua nova versão, traz além das tecnologias já citadas a implementação da programação cross-browser (estilo de programação em que o código funciona em qualquer browser em diferentes plataformas), a qual tem como desvantagem um aumento substancial no tempo de programação, mas, em contrapartida, tem como sua maior vantagem a ampliação do número de possíveis usuários.

O ETC permite que os usuários salvem seus textos em diferentes extensões como .pdf, .txt e .html., afim de facilitar a visualização dos documentos criados em qualquer plataforma, isto é, em qualquer computador e sistema operacional.

\section{Conhecendo o Ambiente}

O planejamento do editor teve como prioridade a constituição de uma Interface Gráfica prática e amigável, encaixando-se nos critérios de usabilidade. Sob esta perspectiva, a localização de cada elemento da tela, como links, botões, textos, entre outros foi cuidadosamente pensada de forma a facilitar a experiência do usuário. Os elementos foram agrupados e posicionados de acordo com a função que exercem dentro do editor, a fim de que pudessem ser localizados pelo contexto de sua utilização. Para escapar de uma navegação linear, a interface do ETC abusa dos recursos do hipertexto, tendo sempre na tela uma forma de acessar todos os recursos disponíveis no mínimo em três clicks de maneira intuitiva. Além disso, cuidou-se para que o software se tornasse 
dinâmico na medida em que o usuário pode escolher quais recursos utilizar, sendo que os não utilizados não ficam disponíveis na tela.

Na Figura 1 encontra-se a área de edição do texto. A mesma é dividida em quatro partes. A primeira corresponde à visualização do texto, na parte central. A segunda, localizada à esquerda, trata da barra auxiliar onde está o mural, o mapa e o botão para o histórico do texto, além da listagem dos participantes. A terceira, localizada à direita, é a barra de ferramentas com os ícones que realizam as funções de edição, sendo elas: editar, comentar, inserir parágrafo, inserir seção, histórico do parágrafo, lixeira e restaurar lixeira. Por fim, a barra de edição, que se encontra na parte superior. Nela o usuário pode trocar o conteúdo e a aparência do texto.

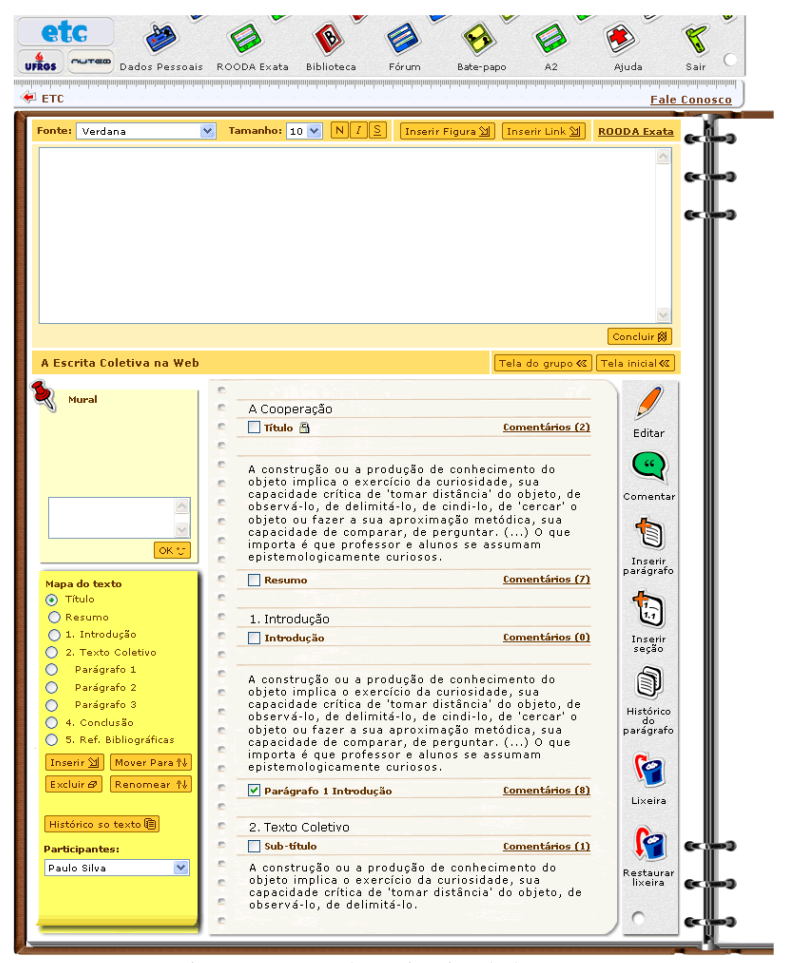

Figura 1 - Tela principal do texto.

Outra tela do ETC a destacar é a do Histórico. Nesta, a visualização de versões anteriores encontra-se sempre disponível, podendo ser acessadas pelo texto inteiro ou por cada parágrafo/seção. No Histórico o texto é visualizado à esquerda e à direita encontram-se listados os autores e os botões para acessar as cinco últimas versões dentro do editor, ou versões mais antigas em formato xml. Quando o usuário clica em um dos autores o texto à esquerda fica assinalado com uma cor diferente nas passagens que foram feitas ou alteradas pelo autor escolhido. Quando se clicar em uma das cinco últimas versões, o texto ficará assinalado com uma cor diferente nas passagens que foram alteradas na versão escolhida. No canto inferior da tela encontra-se um botão para retornar a cor padrão do texto. Uma das principais vantagens da ferramenta Histórico é poder acompanhar o processo de construção do texto tanto em âmbito coletivo quanto individual e, desta forma, trabalhar com as particularidades deste desenvolvimento. 


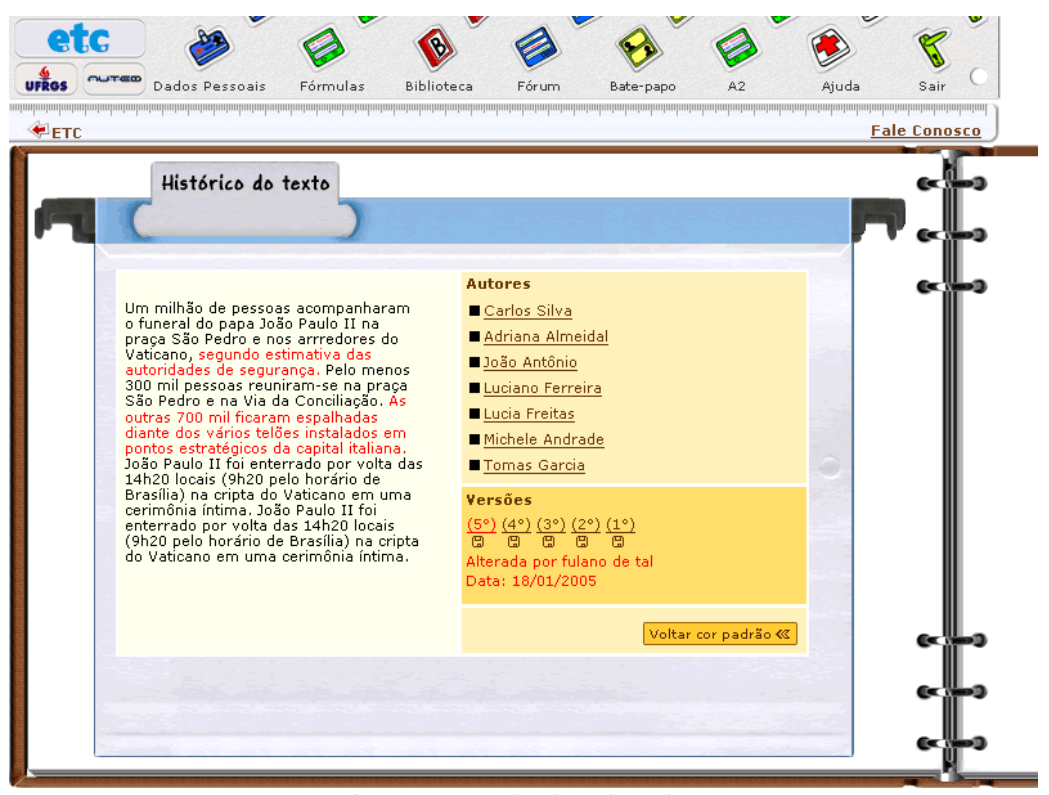

Figura 2 - Tela do Histórico.

Abaixo, na Figura 3, encontra-se a tela de acesso aos textos. Nela, o usuário encontra listados os grupos dos quais faz parte, sendo que aqueles em que ele é gerente estão marcados com uma estrela. Nesta mesma tela estão as funcionalidades Mural do grupo e Lembretes, além do campo para se realizar a busca de textos. Por fim, se o usuário tiver o status de administrador ele encontra também o botão para a administração do sistema.

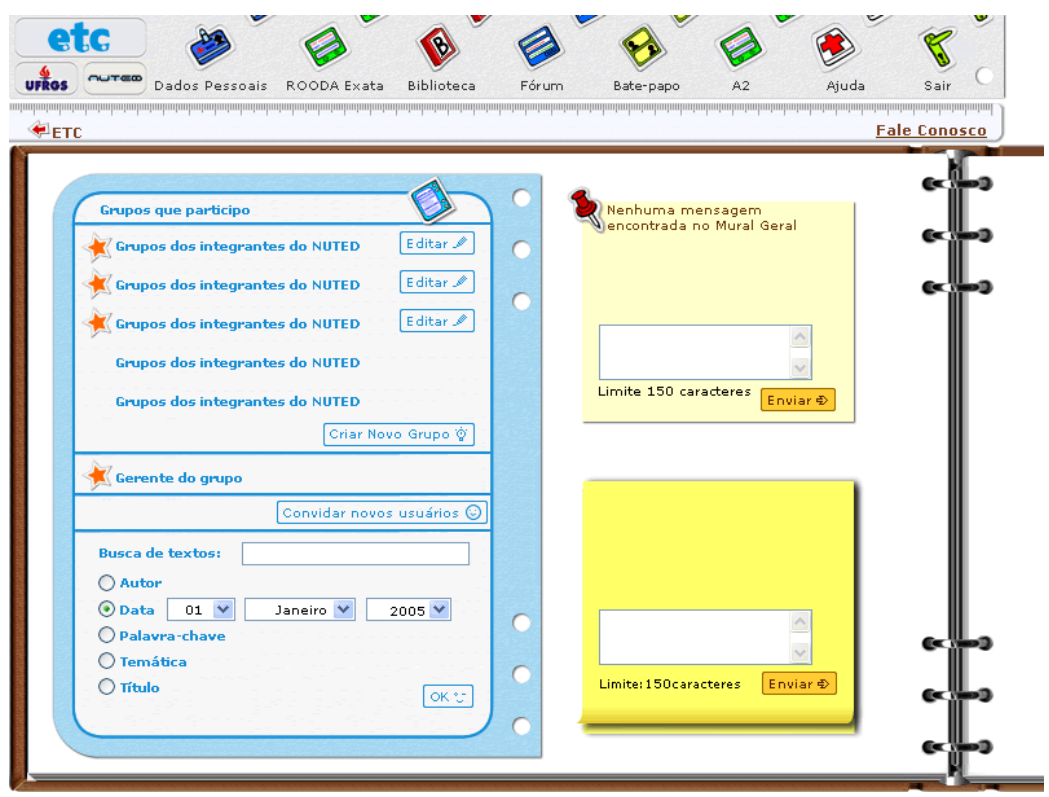

Figura 3 - Tela inicial do ambiente.

\section{Personalizando o Editor}

A seguir são listados alguns itens que tornam o ETC personalizável:

\section{Escolha do documento de identificação}

O usuário que baixa o programa e o instala no sistema é chamado super-usuário. Durante a instalação ele pode escolher qual o documento será utilizado para o registro dos participantes inscritos. Assim, o documento pode ser escolhido de acordo com a instituição. 
Modos de edição e construção do texto

A edição de um texto pode ser realizada de duas formas no editor; por parágrafo: nesta opção os parágrafos são tratados individualmente, mantendo a relação com os demais. Por seção: nesta o texto é editado numa seção inteira, a qual compreende um conjunto de parágrafos que correspondem a um mesmo título ou subtítulo.

Tipos de Autoria

Tanto na edição por parágrafo, quanto na edição por seção os usuários poderão escolher a modalidade de autoria única ou coletiva. Na primeira, cada usuário é "dono" do seu parágrafo, sendo que os colegas não podem alterar, mas sim colaborar com novos parágrafos ou ainda, comentar os postados pelo autor. Na segunda opção, autoria coletiva, todos os usuários que participam do texto podem alterar, comentar, excluir e acrescentar parágrafos. Desta forma, são caracterizados os co-autores, uma vez que todos contribuem numa mesma construção. Em resumo, um usuário não pode alterar o que o outro escreveu, porém pode comentá-lo ou complementá-lo com um novo parágrafo. Tanto a forma de edição, quanto a opção de autoria são escolhidas pelo gerente do grupo. Outras opções, descritas ao longo desta seção, podem ou não ser habilitadas pelo gerente do texto.

Estrutura de Grupos ao invés de Disciplinas

O maior conjunto de organização dentro do ETC são Grupos, dentro dos quais podem ser criados vários Textos. Essa nomenclatura foi escolhida no lugar de 'disciplinas', por exemplo, para o caso do uso do editor por pessoas não interligadas via instituição de ensino. Mesmo assim, o software obedece a uma hierarquia dos tipos de usuário. $\mathrm{O}$ usuário que instala e faz as considerações iniciais do sistema é o Super-usuário. Este pode convidar novos usuários e determinar a eles o status de Administrador, ou não. Somente os que tiverem status de Administrador podem criar novos Grupos. O criador do grupo fica sendo Gerente do Grupo. Dentro do Grupo qualquer participante pode criar um novo Texto, sendo que o criador do Texto é tido como Gerente do Texto.

\section{Funcionalidades}

O editor possui 21 funcionalidades podendo ser divididas em funcionalidades de navegação principal e funcionalidades de apoio. As de navegação principal são as relacionadas diretamente com a criação e edição dos grupos textos. Elas se encontram na área de trabalho das telas podendo ser acessadas por ícones, botões e links. Sendo elas:

- Criar/editar grupo: para criar e editar configurações do grupo.

- Criar/editar texto: para criar e editar configurações do texto.

- Edição do texto: para editar os parágrafos/seções do texto.

- Bloqueio de parágrafo: o participante pode reservar um parágrafo para editar posteriormente.

- Entrar na fila de edição: quando um parágrafo encontra-se bloqueado, outros participantes podem entrar na fila de edição deste.

- Inserir parágrafo/Inserir seção: o usuário pode selecionar um outro parágrafo/seção já existente e inserir um o novo antes ou depois do selecionado.

- Comenta: comentários individuais por parágrafo/seção.

- Histórico: pode-se visualizar as últimas cinco alterações por ordem cronológica, e por autor, tanto do texto como do parágrafo.

- Lixeira: pode-se mandar arquivos para a lixeira e restaurar os mais recentes. 
- Mapa do texto: auxilia na organização do texto em títulos, subtítulos e parágrafos antes mesmo de se começar a escrever. Também são fornecidas estruturas prémontadas das quais o usuário pode fazer uso.

- Mural do grupo: contém notícias do sistema e gerente do grupo.

- Mural do texto: contém notícias do sistema e gerente do texto.

- Lembretes: o usuário deixa lembretes a si mesmo.

- Busca de textos: podendo ser em todo sistema ou em um determinado grupo.

- Salvar texto: as cópias podem ser salvas em PDF ou TXT ou HTML.

As funcionalidades de apoio são encontradas no menu superior, servem para promover a interação/comunicação entre os usuários, além de proporcionar o armazenamento e consulta de conteúdos relacionados. Sendo elas:

- Dados pessoais: perfil do usuário.

- A2: ferramenta para comunicação síncrona entre usuários.

- Bate-papo: sala de bate-papo entre os participantes de um texto.

- Fórum de discussão: para discussão de assuntos referentes ao texto.

- Biblioteca: para armazenamento de materiais de apoio.

- ROODA exata: ferramenta com caracteres para a edição de fórmulas das ciências exatas. Estas poderão ser inseridas tanto no texto quanto na comunicação entre os usuários através do A2, fórum e bate-papo.

\section{Testando o Editor}

No semestre de $01 / 2006$, foi feito um projeto piloto em duas disciplinas ${ }^{\mathrm{i}}$, com a versão Stand Alone, a fim de realizar uma primeira avaliação durante o seu ciclo de desenvolvimento (somente algumas funcionalidades estavas implementadas). A diversidade do público selecionado foi intencional, uma vez que o editor foi pensado e desenvolvido com o objetivo de atender diferentes demandas e necessidades institucionais/empresariais.

Atualmente o grupo de pesquisa está analisando/categorizando os dados coletados a fim de relacioná-los com a teoria que sustentou o desenvolvimento do ETC. A articulação entre teoria e prática faz-se necessária neste momento, pois quer-se relacionar os dados coletados com os princípios teóricos que sustentaram o planejamento e desenvolvimento do editor, para saber se os pressupostos/objetivos pensados foram atingidos ou não. Além disso, neste momento de testagem, está-se coletando/analisando sugestões dos usuários, as quais serão implementadas na medida do possível, sempre visando a melhoria do software, bem como o aproveitamento do sujeito nesta relação. Após esta primeira implementação, tem-se como meta sanar os bugs naturais do software que está sendo utilizado pela primeira vez, bem como agregar possibilidades de recursos que venham a ser apontadas pelos sujeitos que estão atualmente fazendo uso do Editor.

Logo, a partir dos dados coletados, pretende-se constatar se o ETC, com suas ferramentas de apoio e seu planejamento (baseado em estudos sobre o design da interação), facilita a cooperação/colaboração, comunicação, coordenação e negociação entre os usuários, quais são as funcionalidades que devem ser repensadas e construídas ou re-construídas em função das sugestões/contribuições dos participantes da disciplina.

\section{Considerações Finais}

O ETC é uma ferramenta de apoio ao trabalho/aprendizagem em grupo e tem por objetivo oferecer suporte para que todos os usuários, mesmo com diferentes necessidades, possam constituir uma coletividade apoiada na Web. 
Os critérios de usabilidade e design de interface tem importante destaque na implementação do ETC já que foram planejados com o objetivo de tornar a ferramenta intuitiva e de fácil navegação. Além disso, o editor proporciona suporte à coordenação de ações durante o processo de escrita, permitindo que os diversos olhares sobre o mesmo objeto possam ser analisados, discutidos, favorecendo o contexto/construção do conhecimento.

Atualmente, a pesquisa encontra-se em fase de coleta de dados. Algumas necessidades apresentadas pelos sujeitos estão sendo atendidas de forma imediata e outras continuam em análise e planejamento para serem implementadas no próximo semestre (2006/02) no editor. Destaca-se que a busca pelo aperfeiçoamento do ETC apoiada num processo investigativo, contribui para as relações de construção entre os sujeitos, bem como para a qualidade do software a que o grupo se propôs a desenvolver. Estima-se que ainda neste ano este processo seja concluído e o software seja disponibilizado a toda a comunidade acadêmica.

\section{REFERÊNCIAS BIBLIOGRÁFICAS}

Behar, P. A., et al. ROODA - Rede cOOperativa De Aprendizagem: Uma plataforma de suporte para aprendizagem a distância. In: Informática na Educação - Teoria e Prática. Programa de Pós-Graduação em Informática na Educação - Porto Alegre: UFRGS. Vol. 4 N. 2, 2001, p.87-96.

Behar, P. A.; et al. Construção e Aplicação do ETC - editor de texto coletivo. In: BARBOSA, Rommel Melgaço. (Org.). Ambientes Virtuais de Aprendizagem. Porto Alegre, Vol. único, 2005, p. 17-28.

Bakhtin, M. M., Estética da Criação Verbal. São Paulo: Martins Fontes, 2000.

Preece, J. Rogers, Y. Sharp, H. Design de Interação: além da interação homem-computador. Porto Alegre: Bookman. 2005.

Piaget, J., Estudos Sociológicos. Rio de Janeiro: Forense, 1973.

Piaget, J., Abstração Reflexionante: relações lógico-matemáticas e ordem nas relações espaciais. Porto Alegre: Artes Médicas, 1995.

\footnotetext{
' EDU 3375 - O computador na Educação, do Curso de Pedagogia da Faculdade de Educação e Oficinas Virtuais de Aprendizagem do Curso de Pós em Informática na Educação, ministradas pela Profa. Patricia Alejandra Behar.
} 